\title{
MULTI BAND MICRO STRIP PATCH ANTENNA FOR WIRELESS APPLICATIONS
}

*Lina M. Nori ${ }^{1}$

Raad H. Thahir ${ }^{1}$

\begin{abstract}
This research paper aims to design a new shape of the microstrip patch antenna. Combining a half circular and zigzag shape of a triangular patch antenna, we selected two different shapes of microstrip patch to obtained modern shape no one mentioned it before and it's seems like a tulip rose, so this design achieved to works for multiband. The dimensions of the proposed antenna are $(38 \times 30 \times 1.6) \mathrm{mm}^{3}$ applied on the dielectric substrate FR-4, which has a relative dielectric constant of $(\varepsilon r=4.3)$ and loss tangent ( $\tan \delta=0.002$ ). Both patch and ground are copper material with a thickness $(\mathrm{t}=0.035 \mathrm{~mm})$. So fourband are achieved (5.1612-5.3874) GHz, (8.8729-10.067) $\mathrm{GHz}$, (10.476-11.091) GHz, and (13.819-30) GHz. The return loss (S11) are (-20.784) dB, (-30.532) dB, (-19.246) $d B$ and $(-29.789) d B$ respectively. The antenna is printed by using FR-4 substrate and simulated by CST-Microwave studio software. This antenna works for various wireless applications such as Wi-Fl, $\mathrm{C}$ band, $\mathrm{X}$ band, Ku band, Kaband, cellular phones, and satellite communications.
\end{abstract}

Keywords: $C, X, K u, K a$ bands, multi band, circular microstrip patch antenna.

\section{Introduction}

The interest in multi-band antenna is increasing, especially in order to limit the variety of antennas embedded in combining multiple functions in one antenna [1], [2]. To reduce the cost when used single antenna for worked in multiband. There are several methods for gaining multi-band [3], using model characterization from slots and fractals or etc. Recent wireless communication systems need to lightweight, low profile, high efficiency, high gain and simple structure [4]. Most approved for mobile applications and aerospace [5]. The microstrip patch can take any shapes, although circular and rectangular are commonly used, through the shapes that attracted recently is the triangular patch antenna shaped, The main advantage of made a multiband microstrip patch antenna for elimination the number of devices [6]. This paper presents a microstrip patch antenna with half circular patch and zigzag in the upper with one slot etched in the radiating patch to provide a multiband.

\section{The Proposed Microstrip Patch Antenna}

This proposed microstrip patch antenna fabricated to works for fourth bands, so for operating in the wireless communication WLAN, WiMAX, C- band, and -X band frequency ranges [7].Because we need to used one antenna worked in multi-bands than used many antenna for worked in one band only. The design issues include antenna shapes, necessary equations, parametric study The shapes of micro-strip patch Antenna It's a new mixing of two shapes of micro-strip patch as the first shape in the below a half circular with radius ( $\mathrm{r}=8$ ) and Zig-zag four triangle in a row above to more special shape, as shown in figure(1). 
To gain the correct results we must used some of equations to give more assist when we select the specification of the design so firstly to achieve the half circular microstrip patch antenna we need to calculated, the dimension of the circular microstrip antenna (a). It can be determined by the resonance frequency $\left(\left(f_{r}\right)\right.$ by [8]

$\mathrm{a}=\frac{\mathrm{F}}{\sqrt{1+\frac{2 \mathrm{~h}}{\pi \varepsilon_{\mathrm{r}} \mathrm{F}\left[\ln \left(\frac{\mathrm{F} \pi}{2 \mathrm{~h}}\right)+1.7726\right]}}}$

$\mathrm{F}=\frac{8.791 \times 10^{9}}{\mathrm{f} \sqrt{\varepsilon_{\mathrm{r}}}}$

The ground plane is an area which located in the bottom. the ground plane dimension can be determined by [9]

$L_{g}=6 \mathrm{~h}+L_{p}$

$W_{g}=6 \mathrm{~h}+W_{p}$

The feed length $\left(L_{f}\right)$ and feeder width $\left(W_{f}\right)$ can be expressed by [10]

$\mathrm{L}_{\mathrm{f}}=\frac{\lambda_{\mathrm{g}}}{4}$

$\lambda_{\mathrm{g}}=\frac{\lambda}{\sqrt{\varepsilon_{\text {reff }}}}$

$\lambda=\frac{\mathrm{c}}{\mathrm{f}}$

$\varepsilon_{\mathrm{reff}}=\frac{\varepsilon_{\mathrm{r}}+1}{2}+\frac{\varepsilon_{\mathrm{r}}-1}{2}\left[1+\frac{12 \mathrm{~h}}{\mathrm{~W}}\right]^{-0.5}$

$\mathrm{W}_{\mathrm{f}}=\frac{\mathrm{c}}{2 \mathrm{f}_{\mathrm{r}} \sqrt{\frac{\varepsilon_{\mathrm{r}}+1}{2}}}$

\section{Parametric Study}

After the calculation of the parameter theoretically with the all above equations, we obtain the simulation results as shown in figure (2).

\subsection{The Effect of Ground Width $\left(\mathrm{W}_{\mathrm{g}}\right)$}

The variation of $S_{11}$ with frequency is shown in figure (3), it is noted that the best value of $\mathrm{W}_{\mathrm{g}}$ is $25 \mathrm{~mm}$.

\subsection{The Effect of Ground Length $\left(L_{g}\right)$}

The variation of $S_{11}$ with frequency is shown in figure (4), it is note that the best value of $L_{g}$ is $27 \mathrm{~mm}$.

Finally Figure (5) show the optimum simulation results.

\section{Results}

\subsection{Figures}

Figure (1) shown the proposed multi band microstrip patch antenna and it's dimension, having new mixing shapes of a half circular shape in the below and zigzag above edging like triangular with one circle slot in the patch to obtain a multi bands, and it operates at (5.161230) $\mathrm{GHz}$ bands.

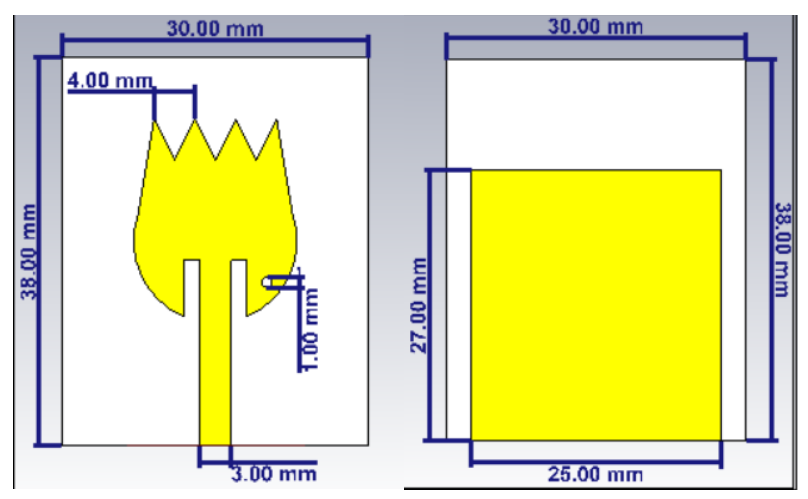

Figure 1. Geometry of the proposed multi band microstrip patch antenna

Figure (2) shown the return loss $\left(\mathrm{S}_{11}\right)$ results from we apply the calculation we gained from equation only, it's appears not practical and not good results, so we made a parametric study. 


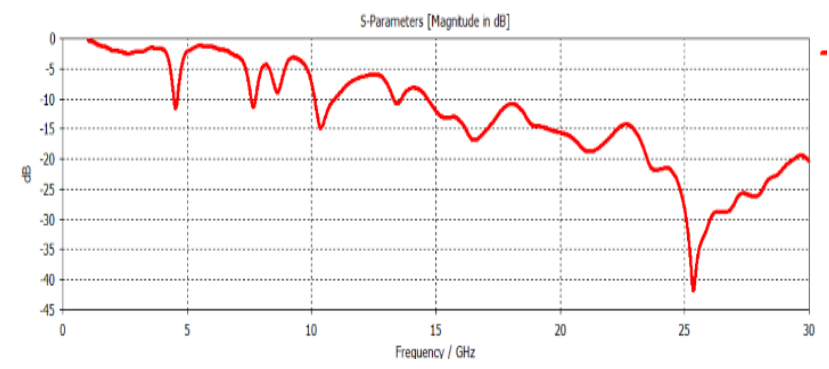

Figure 2. $\mathrm{S}_{11}$ result when using the equations above

Figure (3) shown the return loss $\left(\mathrm{S}_{11}\right)$ curve when we made a parametric study with change the value of $W_{g}$ and this is the most optimum three values when

$W_{g}=24 \mathrm{~mm}, 25 \mathrm{~mm}, 26 \mathrm{~mm}$ respectively, so we choose $W_{g}=25 \mathrm{~mm}$.

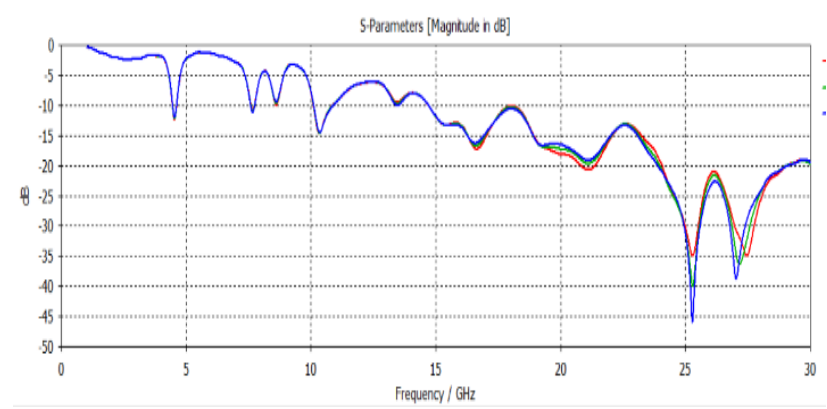

Figure 3. Show the simulation of the return loss $\left(\mathrm{S}_{11}\right)$ value with frequency for $W_{g}$

Figure (4) shown the return loss $\left(\mathrm{S}_{11}\right)$ curve when we made a parametric study with change the value of $L_{g}$ and this is the most optimum three values when

$L_{g}=26 \mathrm{~mm}, 27 \mathrm{~mm}, 28 \mathrm{~mm}$ respectively, so we choose $L_{g}=27 \mathrm{~mm}$.

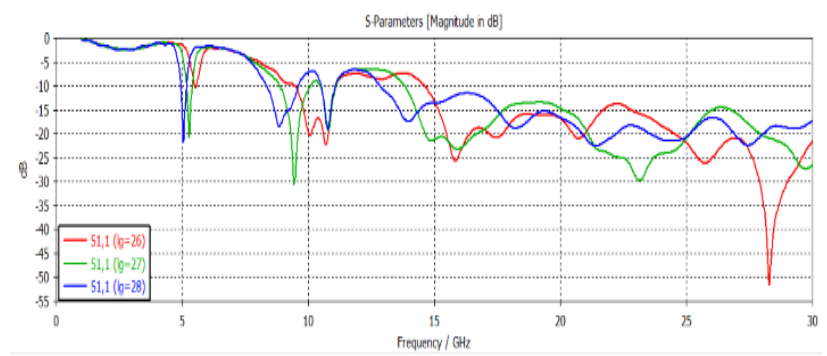

Figure 4. Show the simulation of the return loss $\left(S_{11}\right)$ value with frequency for $L_{g}$
Figure (5) shown the optimum values after change the $W_{g}, L_{g}$ and made a one small slots in the right down side of the patch with $\mathrm{r}=0.5 \mathrm{~mm}$.

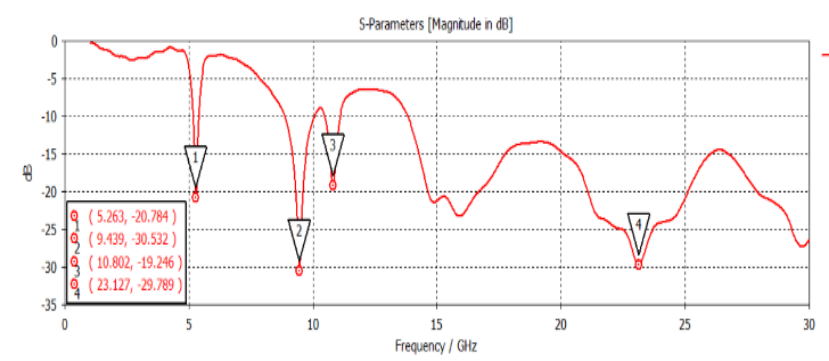

Figure 5. Show the optimum simulation of the return loss $\left(S_{11}\right)$ value with frequency

Figure 6 shown the values of gain, and it's in facts when the frequency equals to $(5.263 \mathrm{GHz})$ the gain less than $5 \mathrm{~dB}$, so the value of gain $=11 \mathrm{~dB}$ it's not in the range we used.

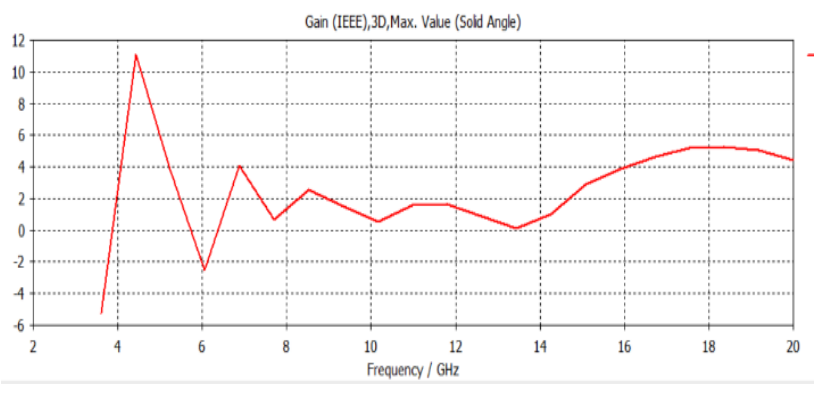

Figure 6. Show the variation of gain with frequency for multi-band

\subsection{Tables}

Table 1. The antenna parameters theoretical calculations values

\begin{tabular}{cl}
\hline Antenna Parameters & Value $(\mathrm{mm})$ \\
\hline$W_{g}$ & 30 \\
$L_{g}$ & 38 \\
$W_{s}$ & 30 \\
$L_{s}$ & 38 \\
$t$ & 0.035 \\
$h$ & 1.6 \\
$L_{f}$ & 12.2 \\
$W_{f}$ & 3 \\
$a$ & 8 \\
$S$ & 4 \\
$\mathrm{r}$ & 0.5 \\
\hline
\end{tabular}


Table 2. The antenna parameters optimum

\begin{tabular}{cl}
\multicolumn{2}{c}{ values } \\
\hline Antenna Parameters & Value(mm) \\
\hline$W_{g}$ & 25 \\
$L_{g}$ & 27 \\
$W_{s}$ & 30 \\
$L_{S}$ & 38 \\
$t$ & 0.035 \\
$h$ & 1.6 \\
$L_{f}$ & 12.2 \\
$W_{f}$ & 3 \\
$a$ & 8 \\
$S$ & 4 \\
$\mathrm{r}$ & 0.5 \\
\hline
\end{tabular}

\section{Conclusions}

This work focuses on the design and simulation of a microstrip patch antenna. A modern microstrip patch antenna is outlined and implemented to function for multiband. The estimate of the proposed antenna is $(38 \times 30 \times 1.6) \mathrm{mm}^{3}$. It can be utilized for $\mathrm{Wi}-\mathrm{Fi}$, $\mathrm{C}$ band, $\mathrm{X}$ band, for satellite communications, cellular phones, $\mathrm{Ku}$ and $\mathrm{Ka}$ bands.

As a future work, we can fabricate such antenna and investigate the effect of substrate and other factors, in addition one can investigate the source of error.

\section{Acknowledgements}

The authors thank Al-Mustansiriyah University for providing the opportunity for this research work.

\section{Conflict of interest}

The publication of this article causes no conflict of interest.

\section{Abbreviations}
a
radius of circular patch
$\mathrm{h}$
height of the substrate

$\begin{array}{ll}f & \text { resonance frequency in hertz } \\ \varepsilon_{r} & \text { effective dielectric constant of } \\ L_{g} & \text { length of ground plane } \\ W_{g} & \text { width of ground plane } \\ L_{p} & \text { Length of patch } \\ W_{p} & \text { Width of patch } \\ L_{f} & \text { Length of transmission line } \\ f_{r} & \text { resonance frequency } \\ \varepsilon_{r e f f} & \text { effective relative dielectric constant } \\ \mathrm{a} & \text { radius of circular patxh } \\ \mathrm{S} & \text { The upper zigzag triangular } \\ \mathrm{r} & \text { radius of circle slot in patch } \\ \mathrm{t} & \text { Thickness of copper } \\ W_{f} & \text { width of transmission line } \\ \lambda_{g} & \text { guided wavelength } \\ \lambda & \text { free space wave length } \\ c & \text { speed of Light }\end{array}$

\section{References}

1. Adegoke. O.M., and Hong-Xing. Z., (2015). "Design of Multiband Microstrip Antenna for Mobile Wireless Communication".3rd International Conference on Management, Education, Information and Control (MEICI'2015), Shenyang, China.

2. Sharma. V., and Patidar. D.K.,(2017) "Design and Analysis of Staked Multiband Microstrip Antenna". International Journal of Advanced Research in Computer and Communication Engineering ISO 3297.

3. Sittironnarit. T. and Ali. M. (2002). "Analysis and Design of Dual-Band Folded Microstrip Patch Antenna for Handneld Device Applications". Southeast Conference, IEEE Proceedings, pp. 255-258.

4. Huque. T.I., Hossain. K., Islam. S., and Chowdhury. A. (2011). " Design and Performance Analysis of Microstrip Array Antennas With Optimum Parameters For X-band 
Applications". International Journal of Advanced Computer Science and Applications, pp. 81-87.

5. Garg. R., Bhartia. P., Bahl. I.J., and Ittipiboon. P. (2001). " Microstrip Antenna Design Handbook" Artech House, Boston. London.

6. Olaimat. M.M., and Dib. N.I. (2011). " A Study of $15^{\circ}-75^{\circ}-90^{\circ}$ angles Triangular Patch Antenna". Progress In Electromagnetics Research (PIER). pp. 1-9.

7. Stewart. J., Nickerson. C.,Lewis. T.(2020). "5G Mid-Band spectrum global update".

Falade. O., Ur Rehman. M., Gao. Y.,Chen. X., and Parini. C.(2012). "Single feed stacked patch circular polarized antenna for trip 